\title{
Analysis of mtDNA/nDNA ratio in mice
}

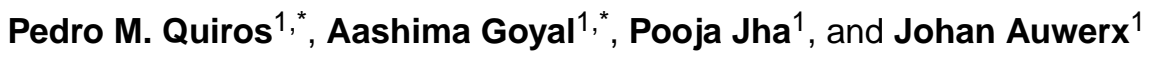 \\ ${ }^{1}$ Laboratory for Integrative and Systems Physiology, Ecole Polytechnique Federale de Lausanne, \\ 1015 Lausanne, Switzerland
}

\begin{abstract}
The mitochondrial DNA (mtDNA) lacks a protection provided by the nucleosomes in the nuclear DNA and does not have a DNA repair mechanism, making it highly susceptible to damage, which can lead to mtDNA depletion. MtDNA depletion compromises the efficient function of cells and tissues and thus impacts negatively on health. Here, we describe a brief and easy protocol to quantify mtDNA copy number by determining the mtDNA/nDNA ratio that we validated in a cohort of young and aged mice.
\end{abstract}

\author{
Keywords \\ qPCR; mtDNA; ND1; 16SrRNA
}

\section{INTRODUCTION}

Mouse mitochondrial DNA (mtDNA) is a double-stranded circular DNA with an approximate size of 16.6-kb, which encodes 37 genes: 22 transfer RNAs (tRNA), 2 ribosomal RNAs (rRNA), and 13 polypeptides. These 13 polypeptides are protein subunits of the oxidative phosphorylation (OXPHOS) complexes I, III, IV, and V, while the tRNAs and rRNAs are required to translate these mtDNA-encoded polypeptides. The rest of the mitochondrial proteome, composed of $\sim 1,500$ proteins, is encoded in the nuclear DNA (nDNA). Both mtDNA strands, which differ in their nucleotide content, encode different genes: the heavy strand (H-strand), rich in guanine, encodes 28 genes (2 rRNAs, 14 tRNAs, and 12 polypeptides), while the light strand (L-strand), rich in cytosine, encodes only 8 tRNAs and a single polypeptide, ND6. Each mtDNA strand is transcribed continuously, generating a polycistronic RNA, in which almost all protein-coding regions are separated by tRNAs genes, except for ATP8-ATP6 and ND4L-ND4 that are overlapping genes (Figure 1). MtDNA is maternally inherited and is redundant, being present in multiple copies in each mitochondrion. Each mouse cell, or in general each animal cell, contains between 100 and 10,000 copies of mtDNA, although these numbers vary widely between cell type, tissue and

Contact information: Laboratory of Integrative and Systems Physiology (LISP), EPFL, SV, Station 15, CH-1015 Lausanne,

Switzerland, admin.auwerx@epfl.ch, Phone: +41 2169395 22, Fax: +41 216939600.

${ }^{*}$ These authors contribute equally to this work

CONFLICTS OF INTEREST

The authors have no conflicts of interest for this article. 
developmental stage, as well as in several pathological conditions and during the aging process (Bogenhagen, 2012).

MtDNA replication is carried out by the nuclear-encoded mitochondrial polymerase $\gamma$ and is regulated by the mitochondrial transcription factor A (Tfam), a component of the mitochondrial nucleoids (Young and Copeland, 2016). In humans, defects in mtDNA maintenance generated by mutations in genes involved in mtDNA replication and nucleotide biosynthesis cause mtDNA depletion syndromes (MDS) (El-Hattab and Scaglia, 2013). Such mtDNA depletions are also associated with metabolic diseases, including type 2 diabetes, cancers and neurodegenerative disorders, including Alzheimer's, Parkinson's and MachadoJoseph disease (Abolhassani et al., 2016; Kazachkova et al., 2013; Ramos et al., 2015; Sepe et al., 2016). During aging, mtDNA copy number also decreases, probably because it is prone to oxidative damage by reactive oxygen species (ROS) produced in the mitochondrial matrix. In addition, the lack of protection by nucleosomes, as in the nDNA, along with the absence of DNA repair mechanisms, also contributes to the accumulation of mtDNA damage, which finally generates mtDNA deletions and depletion. In this regard, several reports have shown that aging leads to mtDNA damage and dysfunction (Bratic and Larsson, 2013; Gomez-Cabrera et al., 2012; Kennedy et al., 2012; Trifunovic and Larsson, 2008). In such cases, quantification of the mtDNA damage and analysis and quantification of the mtDNA copy number may be a good biomarker for disease progression and development of therapies (Kazachkova et al., 2013). In non-pathological or aging-related conditions, mtDNA quantification is also a good indicator of the mitochondrial mass. Since in a normal/healthy physiological state, mtDNA levels remain almost constant, evaluation of the mtDNA copy number can be a good indicator of the amount of mitochondrial mass in a diseased state, although it is recommended to use other complementary techniques to provide additional evidence for disease, such as measurements of citrate synthase activity or specific mitochondrial staining (Quiros et al., 2012).

Analysis of mtDNA content to obtain the mtDNA/nDNA ratio, was classically evaluated by Southern blot or gel electrophoresis, however, these techniques are only semi-quantitative and required higher amounts of DNA than PCR-based techniques. Quantitative PCR (qPCR) is generally being used to quantify and detect mtDNA depletions, but improvements have been made in the application of PCR to achieve better resolution. Recently, a multiplexed real-time PCR strategy was validated that can be used for quantification of mitochondrial DNA copy number (He et al., 2002; Phillips et al., 2014). Here, we provide a protocol for analysis of mtDNA/nDNA ratio in mouse tissues and cells using a SYBR green assay. Our protocol focuses on the estimation of mtDNA copy number, comparing the amount of mitochondrial versus nuclear DNA. We validated our protocol by analyzing the effect of aging on the decrease in the mtDNA content in a cohort of young ( 2 months) and old C57BL/6J (24 months) mice.

Note: All protocols using live animals must first be reviewed and approved by an Institutional Animal Care and Use Committee (IACUC) or must conform to governmental regulations regarding the care and use of laboratory animals. 


\section{BASIC PROTOCOL}

QPCR presents a highly efficient, fast and quantitative technique for estimating relative amounts of known DNA in a sample. With the help of the primers designed for specific amplification of particular mtDNA fragments, the $\mathrm{Ct}$ (threshold cycle) and the relative expression levels of mtDNA can be calculated using qPCR.

Protocol outline (for review purposes only)

DNA isolation from liver (also applies to other organs)

DNA isolation from cells

Quantitative PCR

Data analysis

STEP 1. DNA isolation

MATERIALS-Mouse tissue Take $~ 10-30 \mathrm{mg}$ liver or other tissue.

Mouse cells EDTA (Applichem, A2937,0500)

NaCl (Sigma, 71380)

20\% SDS solution(Applichem, A0675,0500)

Tris(Hydroxymethyl aminomethane) (Biosolve, 0020092391BS)

37\% Hydrochloric acid (Applichem, A0659,1000GL)

$3 \mathrm{M} \mathrm{NaCl}$ solution (see reagents and solutions)

0.5 M EDTA solution (see reagents and solutions)

1 M Tris-HCl solution (see reagents and solutions)

TE buffer (see reagents and solutions)

Lysis buffer (see reagents and solutions)

Ammonium acetate (Fischer, A/3440/50)

7.5 M Ammonium acetate solution (see reagents and solutions)

Ultrapure $^{\mathrm{TM}}$ Phenol: Chloroform: isoamyl alcohol mix (25:24:1, v/v) (Thermofischer, 15593031)

70\% Ethanol (Reactolab, 96170)

Proteinase K recombinant, PCR Grade (20 mg/ml, RPROTK-RO ROCHE, $000000003115836001)$ 
RNase A (5 mg/ml, Thermofisher, EN0531)

PBS pH7.4 (1X) (gibco, Ref.no.10010-015)

\section{Centrifuge}

Tubes 15-ml polypropylene Falcon tubes, 2-ml centrifuge tubes, 1.5-ml centrifuge tubes

NanoDrop 2000 (UV-Vis Spectrophotometer)

qPCR Syber Green Mix (LightCycler ® 480 SYBR Green I Master - Roche Life Science, 4887352001)

Forward and reverse primers (Invitrogen)

16S rRNA forward and reverse primers

FWD: 5'-CCGCAAGGGAAAGATGAAAGAC-3'

REV: 5'-TCGTTTGGTTTCGGGGTTTC-3'

ND1 forward and reverse primers

FWD: 5'-CTAGCAGAAACAAACCGGGC-3'

REV: 5'-CCGGCTGCGTATTCTACGTT-3'

HK2 forward and reverse primers

FWD: 5'-GCCAGCCTCTCCTGATTTTAGTGT-3'

REV: 5'-GGGAACACAAAAGACCTCTTCTGG-3'

384 well plates

Plate seals (ThermalSeal RTS ${ }^{\text {TM }}$ Sealing Films, Z734438)

Double-distilled or Milli Q water

Apparatus

Sterile filter pipette tips, sterile $1.5-\mathrm{mL}$ screw top microcentrifuge tubes

METHOD

A. From liver (applies for other organs as well)

1 Sacrifice a mouse under anesthesia (e.g. 3-5\% isoflurane (Adams and Pacharinsak, 2015)) and excise the liver. Rinse liver briefly with PBS, excise and put a very small piece $(\sim 10-30 \mathrm{mg})$ of liver tissue in an icecold $1.5 \mathrm{ml}$ microcentrifuge tube. Snap frozen tissues stored at $-80^{\circ} \mathrm{C}$ can also be used with this protocol.

Curr Protoc Mouse Biol. Author manuscript; available in PMC 2018 March 02. 
2 Add $600 \mu \mathrm{l}$ of lysis buffer (LB) to the microcentrifuge tube, followed by $0.2 \mathrm{mg} / \mathrm{ml}$ proteinase $\mathrm{K}$ ( $6 \mu \mathrm{l}$ of $20 \mathrm{mg} / \mathrm{ml} \mathrm{stock}$ ), to degrade the proteins present in the tissue sample. Depending upon the tissue sample size, if small, $300 \mu \mathrm{l}$ of $\mathrm{LB}$ and $3 \mu \mathrm{l}$ proteinase $\mathrm{K}$ may also be sufficient.

3 Incubate the samples overnight at $55^{\circ} \mathrm{C}$. A time period of $3 \mathrm{~h}$ also works well for tissue samples weighing up to $10 \mathrm{mg}$ for non-fibrotic tissues like liver.

\section{B. Cells}

1a Remove media from 1 well of a 6 well or 12 well plate. Wash cells with $500 \mu \mathrm{l}$ of PBS solution.

2a Add LB and proteinase K: a volume of $600 \mu \mathrm{l}$ of LB and $6 \mu \mathrm{l}$ of proteinase $\mathrm{K}$ for each well of 6-well plate or $300 \mu \mathrm{l}$ of LB and $3 \mu \mathrm{l}$ of proteinase $\mathrm{K}$ for a 12 -well plate is sufficient.

3a Put the lysate in a microcentrifuge tube and incubate at $55^{\circ} \mathrm{C}$ for $3 \mathrm{hrs}$.

\section{Both tissues and cells}

4 Add RNase A (100 $\mu \mathrm{g} / \mathrm{ml})$ to degrade the RNA present. Incubate at $37^{\circ} \mathrm{C}$ for 30 min. Optionally, a phenol-chloroform extraction can be performed after step 4 if high-quality DNA is required (e.g. next-generation sequencing). Add $600 \mu \mathrm{l}$ of an ultrapure phenol: chloroform: isoamyl alcohol (25:24:1, v/v). Mix well. Centrifuge at 12,000 $\times g$ for 5 min. Transfer the aqueous phase (upper part) carefully to another microcentrifuge tube.

$5 \quad$ Add $250 \mu \mathrm{l}$ ammonium acetate $(7.5 \mathrm{M})$ and $600 \mu \mathrm{l}$ of isopropanol $(0.7 \mathrm{v} / \mathrm{v})$. Mix well. This will result in "DNA jelly fish" like structure that can be clearly seen.

6 Centrifuge at $15,000 \times \mathrm{g}$ for $10 \mathrm{~min}$ at $4^{\circ} \mathrm{C}$. Remove the supernatant. Care should be taken while removing the supernatant so as to not destroy the pellet.

$7 \quad$ Wash with $500 \mu \mathrm{l}$ of $70 \%$ ethanol.

$8 \quad$ Dry the pellet. Resuspend in $100 \mu \mathrm{l}$ of TE buffer.

9 Measure the concentration of DNA using NanoDrop.

10 Dilute the sample using double-distilled water to have a final concentration of 10 ng DNA/ $\mu$ l to be used for qPCR. (Generally an amount of 20-100 ng is used for qPCR, so the final concentration and the volume for qPCR can be adjusted accordingly). Proceed to qPCR.

\section{STEP 2. Quantitative PCR (qPCR)}

Different genes were selected to evaluate the relative copy number of mtDNA and nDNA. In the mouse mitochondrial genome, genes corresponding to the stable fraction that is not prone to deletions encode for 16S rRNA and ND1 (Figure 1) (Tanhauser and Laipis, 1995). Hexokinase 2 (HK2) is a nuclear encoded gene that we selected for our assay. A comparison 
of ND1 and 16S rRNA DNA expression relative to HK DNA expression will give a measure of mtDNA copy number to nDNA copy number ratio. Liver samples of 2 and 24 month old C57BL/6J mice are used in this study as an example.

\section{METHOD}

11 Prepare $100 \mu \mathrm{M}$ primer stock by diluting it with double-distilled water.

12 For each gene, prepare a working stock mastermix of forward and reverse primers with a volume of $100 \mu \mathrm{l}$ each of both forward and reverse primer to have a concentration of $10 \mu \mathrm{M}$ each in a volume of $1000 \mu \mathrm{l}$. Add $800 \mu \mathrm{l}$ of doubledistilled water.

13 In the 384 well plate, add in each well a total volume of $5 \mu$ with the following compositions for different samples using a multichannel pipette. For each gene and each sample, perform the experiment in triplicate.

Components:

DNA: $2 \mu \mathrm{l}$

Syber Green Mix + Forward and reverse primer mix: $3 \mu \mathrm{l}(2.5 \mu \mathrm{l}+0.5 \mu \mathrm{l})$

Total: $5 \mu \mathrm{l}$

14 Cover the plate with plate seal and spin down at top speed (10 seconds) in a plate centrifuge.

15 Put the plate in a thermocycler designed for quantitative measurements.

Conditions of the qPCR: (preamplification step) $95^{\circ} \mathrm{C}$ for $5 \mathrm{~min}$, (amplification step) 45 cycles of $95^{\circ} \mathrm{C}$ for $10 \mathrm{~s}, 60^{\circ} \mathrm{C}$ for $10 \mathrm{~s}$ and $72^{\circ} \mathrm{C}$ for $20 \mathrm{~s}$. Finally a melting curve is calculated to confirm the presence of a single PCR product following these steps: $95^{\circ} \mathrm{C}$ for $5 \mathrm{~s}, 66^{\circ} \mathrm{C}$ for $1 \mathrm{~min}$ and gradual increase in temperature up to $97^{\circ} \mathrm{C}$ (fluorescence adquisition).

\section{DATA ANALYSIS}

Analysis of mtDNA/nDNA ratio can be calculated either by following the classical $\Delta \Delta \mathrm{Ct}$ method used for qPCR analysis or by calculating the number of mtDNA molecules per nDNA molecules. Both methods will generate the same relative results.

$\mathrm{Ct}$ values are calculated using the qPCR machine software. The $\mathrm{Ct}$ of each DNA sample is the mean of the triplicate values of $\mathrm{Ct}$ for each sample (provided the standard deviation (SD) is not more than 0.2). In case of an SD of more than 0.2, the outlier values can be suppressed for the analysis.

\section{A) $\Delta \Delta$ Ct method}

16 Calculate $\Delta \mathrm{Ct}$ using the following formula:

$$
\Delta C t=C t(m t D N A \text { gene })-C t(n D N A \text { gene })
$$


17 Then, calculate the $\Delta \Delta \mathrm{Ct}$ by using the mean of the young cohort as control sample.

$$
\Delta \Delta C t=\Delta C t \text { (Sample of interest })-\Delta C t(\text { Control sample })
$$

18 Finally, calculate the expression of each sample as $2^{-\Delta \Delta C t}$. Import the data into GraphPad Prism for statistical analysis and represent the results using box-andwhisker plot (Figure 2).

\section{B) Number of copies of mtDNA}

16a Alternatively, calculate the number of copies of mtDNA using the following formula:

$$
\Delta C t=C t(n D N A \text { gene })-C t(m t D N A \text { gene })
$$

17a Copies of mtDNA $=2 \times 2^{\Delta \mathrm{Ct}}$

18a Relative $\mathrm{mtDNA}$ content $=\mathrm{mtDNA}$ old $/ \mathrm{mtDNA}$ young .

\section{REAGENTS AND SOLUTIONS}

Use double-distilled or Milli-Q-purified water in all recipes and protocol steps.

\section{$3 \mathrm{M}$ NaCl solution}

Dissolve $175.5 \mathrm{~g}$ of $\mathrm{NaCl}$ powder in $1000 \mathrm{ml}$ of double-distilled water.

\subsection{EDTA solution}

Dissolve 186.12 grams of EDTA powder in $1000 \mathrm{ml}$ of double-distilled water.

\section{M Tris-HCl solution}

Dissolve $121.4 \mathrm{~g}$ of Tris (Hydroxymethyl aminomethane) in $1000 \mathrm{ml}$ of double-distilled water, adjust $\mathrm{pH}$ to 7.4 using hydrochloric acid.

\subsection{Ammonium acetate solution}

Add 578.1 $\mathrm{g}$ of ammonium acetate in $1000 \mathrm{ml}$ of double-distilled water.

\section{Tris-EDTA (TE buffer)}

Mix Tris- $\mathrm{HCl}$ solution ( $1 \mathrm{ml}$ of $1 \mathrm{M}, \mathrm{pH} 7.4)$ and EDTA solution ( $0.2 \mathrm{ml}$ of $0.5 \mathrm{M}$ ) in doubledistilled to have a final concentration of $10 \mathrm{mM}$ and $1 \mathrm{mM}$ respectively in a $100 \mathrm{ml}$ volume of buffer.

Lysis buffer (LB)

Curr Protoc Mouse Biol. Author manuscript; available in PMC 2018 March 02. 
Mix $\mathrm{NaCl}$ solution ( $16.67 \mathrm{ml}$ of $3 \mathrm{M}$ stock), EDTA solution (10 $\mathrm{ml}$ of $0.5 \mathrm{M}$ stock), SDS solution (12.5 ml of $20 \%$ stock) and Tris-HCl solution ( $\mathrm{pH}$ 7.4) (10 ml of $1 \mathrm{M}$ stock) in double-distilled water to have final concentrations of $100 \mathrm{mM}, 10 \mathrm{mM}, 0.5 \%$ and $20 \mathrm{mM}$ respectively for a total of $500 \mathrm{ml}$ buffer.

\section{COMMENTARY}

\section{Background Information}

Analysis of the mtDNA copy number can be done using qPCR. In the example used in this protocol, liver samples from young ( 2 month) and old ( 24 month) C57BL/6J mice were collected and DNA was isolated from them. The DNA (which contained both mtDNA and nDNA) was then used for qPCR for amplification and the ratio of both was calculated. Although qPCR has been shown to be efficient for this analysis in various research articles (He et al., 2002; Phillips et al., 2014), but the detailed procedure has not been described. The advantage of this protocol is the detailed explanation of each and every step carried out and its functional relevance in young and aged mice. In addition, this protocol can be also useful for examining the mtDNA copy number in some mouse pathologies, as in mouse mutants in which increased DNA damage or rapid aging may also lead to depleted mtDNA.

\section{Critical Parameters}

1 Always wear gloves, protective eyewear, and a laboratory coat while handling the detergents

2 This protocol is also applicable to other mouse tissues such as heart and skeletal muscle, brown adipose tissue. It can also be used for cells.

3 It is preferable to use age-matched samples as mtDNA copy number decreases with age.

\section{Troubleshooting}

1 If the tissue is not lysed completely, another $6 \mu \mathrm{l}$ of proteinase $\mathrm{K}$ can be added.

2 With a small amount of tissue or tissues like muscle, the DNA jelly fish structure may not be visible after Step 5, but becomes visible after centrifugation. If the pellet is still not visible, the washing steps should be done carefully to leave enough supernatant at the bottom so that the pellet is not removed.

\section{Anticipated Results}

With this brief protocol, one can easily quantify the mtDNA copy number in mouse tissues. A typical example is shown using the amplification of genes both in mtDNA and in nDNA. The ratio of mtDNA/NDNA decreases by $\sim 75 \%$ in old mice ( 24 months) compared to young mice ( 2 months) and may reflect either a depletion of mtDNA or a decrease in mitochondrial number/content. To verify that the decrease in $\mathrm{mtDNA} / \mathrm{nDNA}$ ratio is a consequence of mtDNA depletion, the amount of mitochondria or the mitochondrial mass should be quantified using other assays, such as the measurement of citrate synthase activity (Quiros et al., 2012). Results of mtDNA copy number vary depending upon the age of the mice used, 
therefore, if comparing different strain or conditions, age-matched mice should be used. We advise that a minimum number of five animals per group should be analysed to obtain consistent and reproducible data.

\section{Time Considerations}

Lysis of the samples is carried out overnight. The initial DNA isolation and dilution takes $\sim 2$ hrs for up to 10 samples. If more than a dozen samples are analysed, it is advisable to do the DNA isolation and dilution on day 1 and to continue with qPCR analysis on day 2. QPCR will take $\sim 120 \mathrm{~min}, 30 \mathrm{~min}$ for preparation and $90 \mathrm{~min}$ for the qPCR run, followed by analysis which may take another $1 \mathrm{hr}$. In total, execution of this protocol will take 2-3 days for completion.

\section{Acknowledgments}

JA is the Nestlé Chair in Energy Metabolism and the research in his laboratory is supported by the EPFL, the NIH (R01AG043930), Krebsforschung Schweiz /SwissCancerLeague (KFS-3082-02-2013), the Systems X program (SySX.ch 2013/153) and the SNSF (31003A-140780).

\section{REFERENCES}

Abolhassani N, Leon J, Sheng Z, Oka S, Hamasaki H, Iwaki T, Nakabeppu Y. Molecular pathophysiology of impaired glucose metabolism, mitochondrial dysfunction, and oxidative DNA damage in Alzheimer's disease brain. Mechanisms of ageing and development. 2016 In press.

Adams S, Pacharinsak C. Mouse anesthesia and analgesia. Current protocols in mouse biology. 2015; 5:51-63. [PubMed: 25727200]

Bogenhagen DF. Mitochondrial DNA nucleoid structure. Biochimica et biophysica acta. 2012; 1819:914-920. [PubMed: 22142616]

Bratic A, Larsson NG. The role of mitochondria in aging. The Journal of clinical investigation. 2013; 123:951-957. [PubMed: 23454757]

El-Hattab AW, Scaglia F. Mitochondrial DNA depletion syndromes: review and updates of genetic basis, manifestations, and therapeutic options. Neurotherapeutics : the journal of the American Society for Experimental NeuroTherapeutics. 2013; 10:186-198. [PubMed: 23385875]

Gomez-Cabrera MC, Sanchis-Gomar F, Garcia-Valles R, Pareja-Galeano H, Gambini J, Borras C, Vina J. Mitochondria as sources and targets of damage in cellular aging. Clinical chemistry and laboratory medicine. 2012; 50:1287-1295. [PubMed: 22868792]

He L, Chinnery PF, Durham SE, Blakely EL, Wardell TM, Borthwick GM, Taylor RW, Turnbull DM. Detection and quantification of mitochondrial DNA deletions in individual cells by real-time PCR. Nucleic acids research. 2002; 30:e68. [PubMed: 12136116]

Kazachkova N, Raposo M, Montiel R, Cymbron T, Bettencourt C, Silva-Fernandes A, Silva S, Maciel P, Lima M. Patterns of mitochondrial DNA damage in blood and brain tissues of a transgenic mouse model of Machado-Joseph disease. Neuro-degenerative diseases. 2013; 11:206-214. [PubMed: 22832131]

Kennedy SR, Loeb LA, Herr AJ. Somatic mutations in aging, cancer and neurodegeneration. Mechanisms of ageing and development. 2012; 133:118-126. [PubMed: 22079405]

Phillips NR, Sprouse ML, Roby RK. Simultaneous quantification of mitochondrial DNA copy number and deletion ratio: a multiplex real-time PCR assay. Scientific reports. 2014; 4:3887. [PubMed: 24463429]

Quiros PM, Ramsay AJ, Sala D, Fernandez-Vizarra E, Rodriguez F, Peinado JR, Fernandez-Garcia MS, Vega JA, Enriquez JA, Zorzano A, Lopez-Otin C. Loss of mitochondrial protease OMA1 alters processing of the GTPase OPA1 and causes obesity and defective thermogenesis in mice. The EMBO journal. 2012; 31:2117-2133. [PubMed: 22433842] 
Ramos A, Kazachkova N, Silva F, Maciel P, Silva-Fernandes A, Duarte-Silva S, Santos C, Lima M. Differential mtDNA damage patterns in a transgenic mouse model of Machado-Joseph disease (MJD/SCA3). Journal of molecular neuroscience : MN. 2015; 55:449-453. [PubMed: 25001003]

Sepe S, Milanese C, Gabriels S, Derks KW, Payan-Gomez C, van IWF, Rijksen YM, Nigg AL, Moreno S, Cerri S, Blandini F, Hoeijmakers JH, Mastroberardino PG. Inefficient DNA Repair Is an Aging-Related Modifier of Parkinson's Disease. Cell reports. 2016; 15:1866-1875. [PubMed: 27210754]

Tanhauser SM, Laipis PJ. Multiple deletions are detectable in mitochondrial DNA of aging mice. The Journal of biological chemistry. 1995; 270:24769-24775. [PubMed: 7559594]

Trifunovic A, Larsson NG. Mitochondrial dysfunction as a cause of ageing. Journal of internal medicine. 2008; 263:167-178. [PubMed: 18226094]

Young MJ, Copeland WC. Human mitochondrial DNA replication machinery and disease. Current opinion in genetics \& development. 2016; 38:52-62. [PubMed: 27065468] 


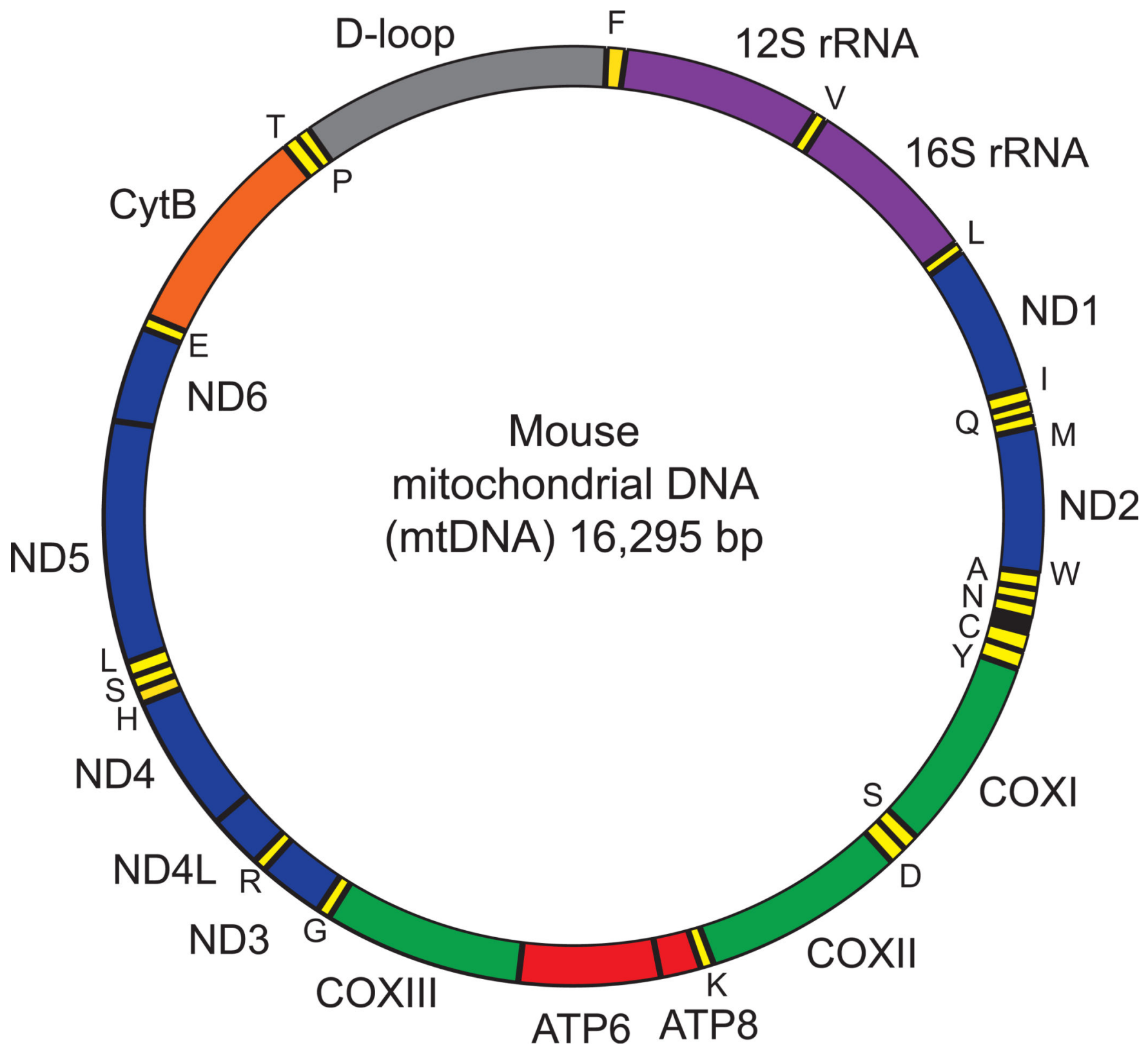

Figure 1. Mouse mitochondrial DNA

The mouse mitochondrial DNA (mtDNA) comprises 16,295 bp. MtDNA forms an inner light strand (L-strand) and an outer heavy strand (H-strand) that encodes different genes. The position of gene names reflects the strand where they are encoded (inside: L-strand: outside: H-strand). Colors identify the different genes: rRNAs (purple), tRNAs (yellow), proteins encoding subunits of the OXPHOS complexes I (blue), III (green), IV (orange) and $\mathrm{V}$ (red). 16S rRNA and ND1 genes are located in the stable part of mtDNA, where no deletions have been reported. 


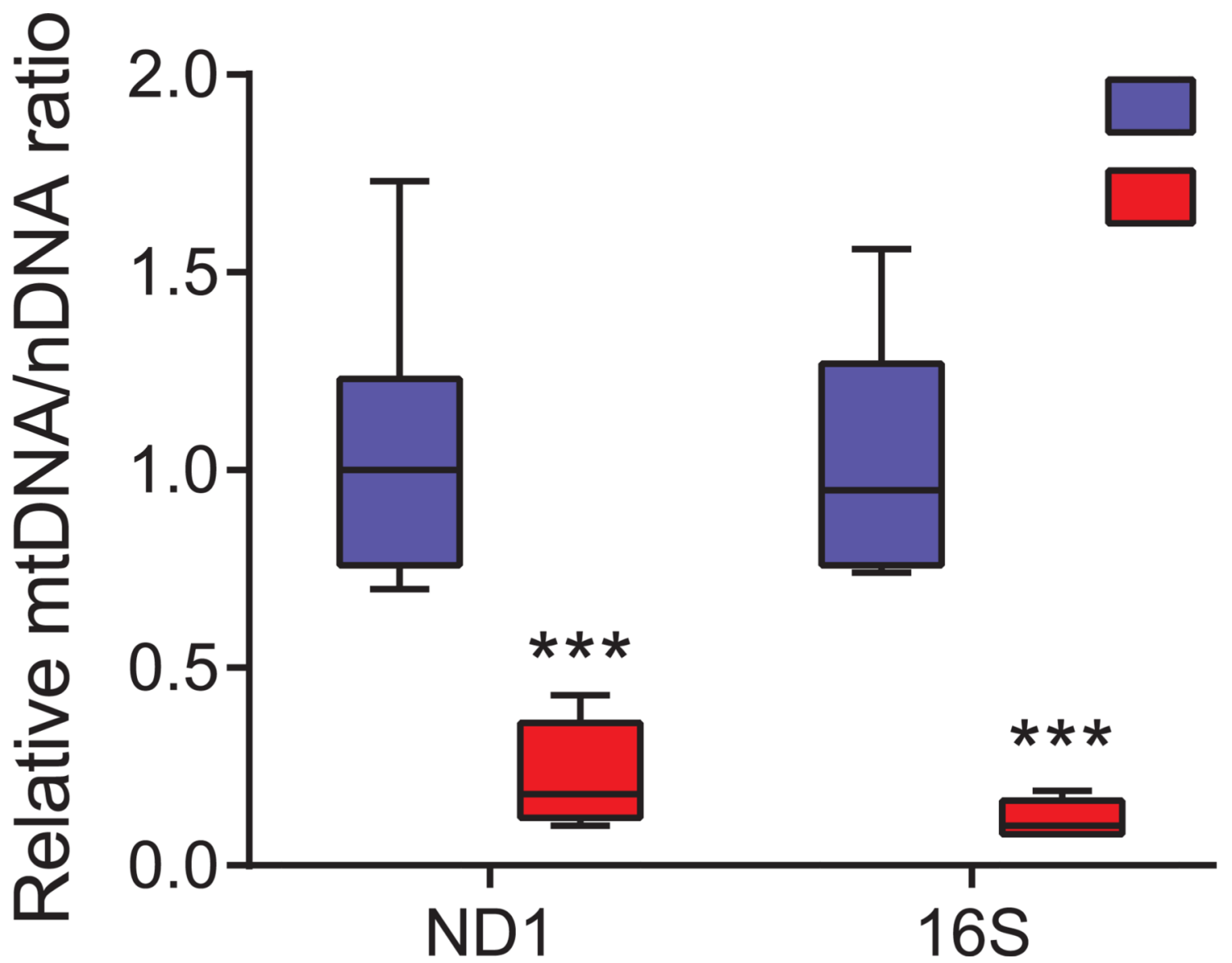

Figure 2. Box plot showing the relative mtDNA levels in young and old C57BL/6J mice Relative quantification was performed on seven young ( 2 months) and five old (24 months) samples in triplicates using qPCR by amplification of ND1 and 16S genes belonging to stable part of mtDNA, and normalised against hexokinase gene (HK). The decrease in $\mathrm{mtDNA} / \mathrm{nDNA}$ ratio in old samples is indicative of the decrease in mtDNA copy number with age. Data are represented as box-and-whisker plot. Statistical differences were calculated using Student's t-test, $* * * \mathrm{P}<0.001$. 